\title{
THE INITIATION OF A TRIAL OF BCG VACCINE FOR LEPROSY
}

\author{
hy James A. McFadzean \\ National Institute for Medical Research, London; and The Research \\ Unit, Sungei Buloh Settlement, Sungei Buloh, Malaya \\ and R. Bhagwan Singh \\ The Institute for Medical Research, Kuala Lumpur, Malava
}

This paper describes the initial laying down of a trial of BCG vaccine as a prophylactic for leprosy. Since the introduction of BCG for tuberculosis, leprologists have discussed its possible value for leprosy. Much indirect work has been undertaken on this question, but the direct approach has largely been ignored. It is clear that the answer can only be supplied in the following manner:

1. By having a static, relatively isolated population with a high incidence of leprosy.

2. The population should be examined clinically for leprosy and then tuberculin tested.

3. The negative tuberculin reactors should be randomised into two groups and one given BCG while the other is left as a control.

4. There should be a constant intake of new born children one half of whom should receive BCG and the other half again left as a control.

5. The population should then be examined at intervals and the incidence of leprosy recorded in each group.

6. The duration of the trial would depend on the size of the population and the incidence of leprosy but a period of 5-10 years would be necessary.

The initiation of such a trial is described in this paper.

\section{Location}

The population chosen for the trial was that of an island called Pulau Ketam which lies in the Klang Straits off the west coast of the Federation of Malaya (see map). The island is a tidal mangrove swamp measuring some 4 miles by 2 miles $(3.2$ by $6.4 \mathrm{~km}$.). The population of 7,369 (1957 census) is entirely Chinese consisting principally of Teochew, Hokkien and Hylam. The only occupation is fishing. As the island is entirely tidal mangrove all the houses are on stilts with the majority concentrated into 3 towns. The houses are crowded together and each house is overcrowded. Sanitary arrangements are simply holes in the floor with the hope that the tide will be high enough in the course of a few days to undertake the flushing. $\mathrm{N}$ o long standing records of the community could be obtained but it is believed that it has existed for at least 100 years. The population 
is static. On the whole, the community is well off as the fishing is good and fish fetch high prices in Malaya. The diet of the population is excellent with a high intake of protein.

There were a number of existing contacts with the island through patients with leprosy who had come from the island to Sungei Buloh Settlement for treatment. The large number of patients from the island suggested that it might be suitable as a place for a BCG trial. A meeting was arranged with the Committee which was responsible for the 'internal affairs' of the island. It was explained that after clinical examination a vaccine would be given to a certain number of the population which would help to protect against tuberculosis and that it might be of value in preventing leprosy. It was stressed that persons found suffering from leprosy would not be compulsorily isolated (as laid down by the existing antiquated law in Malaya). They would be offered the choice of out-patient treatment on the island or of going to the Settlement for in-patient treatment.

Close contact with the population began with the posting of an assistant male nurse and his family to the island. Both the nurse and his wife had been cured of leprosy and had originally come from the island. A small dispensary was established where the nurse could treat minor ailments and gain the confidence of the people. It must be remembered that western medicine is still something new to many Chinese and that their traditional remedies are still believed by many to be the more effective. As it is the practice in Malaya to keep people who have had leprosy on sulphone maintenance treatment for life, the male nurse also carries out the follow-up treatment of patients who have been discharged to the island from the Settlement.

\section{Methods of Survey}

All houses on the island had previously been numbered from 1 upwards for purposes of taxation. These numbers are clearly shown on a plate above the door of each house. There was also available a map of the island (Scale 1 chain/1 inch, i.e., approx. 20 metres $/ 2.5 \mathrm{~cm}$.) showing each house by number. This map had been produced by the Survey Department of Malaya 10 years previously. The male nurse first of all checked all the house numbers, erased from the map houses which had fallen down and added houses which had been built in the preceding 10 years.

All children from 0-12 years had birth certificates and those over 12 years had identity cards with a photograph. These were of great assistance during the survey.

It was decided to start in the town of Pulau Ketam where the density of population was greatest and to restrict the trial to the age group of 0-25 years. Propaganda posters were placed at strategic points in the town and the male nurse visited houses systematically in a given area and recorded the names, ages and sex of all those in 
each house who were in the age group to be investigated. Notice was given to groups of 250 persons-the maximum number of persons who could be dealt with in one day-to present themselves at a central place at a given time. Examinations were conducted in such varied places as a cinema and Chinese temple.

The team which undertook the project was as follows:

(a) Two medical officers.

(b) A nursing sister.

(c) A secretary.

(d) The assistant male nurse.

(e) A technician.

(f) An orderly.

As no suitable accommodation was available on the island for the team, a launch was obtained on which they could live. Owing to other work on hand, the work of the survey could not be undertaken full-time but in blocks of four days allocated as follows:

Day 1. Examine and tuberculin test 250 people.

Day 2. Examine and tuberculin test a further 250 people.

Day 3. Read the tuberculin from Day 1 and administer BCG to the relevant group.

Day 4. Read the tuberculin from Day 2 and administer BCG to the relevant group.

This meant that the great majority of tuberculin reactions were read at 48 hours. The allocation of duties on Days 1 and 2 was as follows:

(a) The orderly ushered the population in, one family at a time.

(b) The assistant male nurse checked the details of the family against his records and acted as the interpreter for the secretary.

(c) The secretary recorded names (Chinese usually have more than one set of names), sex, date of birth, address and father's name. She insisted on seeing every birth certificate or identity card.

(d) One medical officer with the nursing sister examined as much of the skin surface of each person as was permitted. Some difficulty was encountered among the older females. He also examined for nerve enlargement, muscle wasting and contractures of fingers. Records were made of any lesions found. If the person had leprosy, or was suspected of having it, the patient was examined in detail later by himself. Leprosy is much feared by the Chinese and carries a stigma which can never be overcome by an individual and therefore all possible cases of leprosy had to be dealt with confidentially.

(e) The second medical officer tuberculin tested each patient on the flexor surface of the forearm.

$(f)$ The technician supervised the syringes, etc. 
On days 3 and 4 each individual was again carefully checked with his birth certificate or identity card. One medical officer then read the tuberculin reactions and the other vaccinated those who had to be given BCG.

\section{The Tuberculin Test}

(a) Tuberculin employed: The tuberculin employed throughout was that prepared at the State Serum Institute in Copenhagen. This was sent to Malaya in concentrated form and diluted at the Institute for Medical Research in Kuala Lumpur. The bulk of tuberculin employed was RT 22 in doses of 5 TUs in $0.1 \mathrm{ml}$. Subsequently

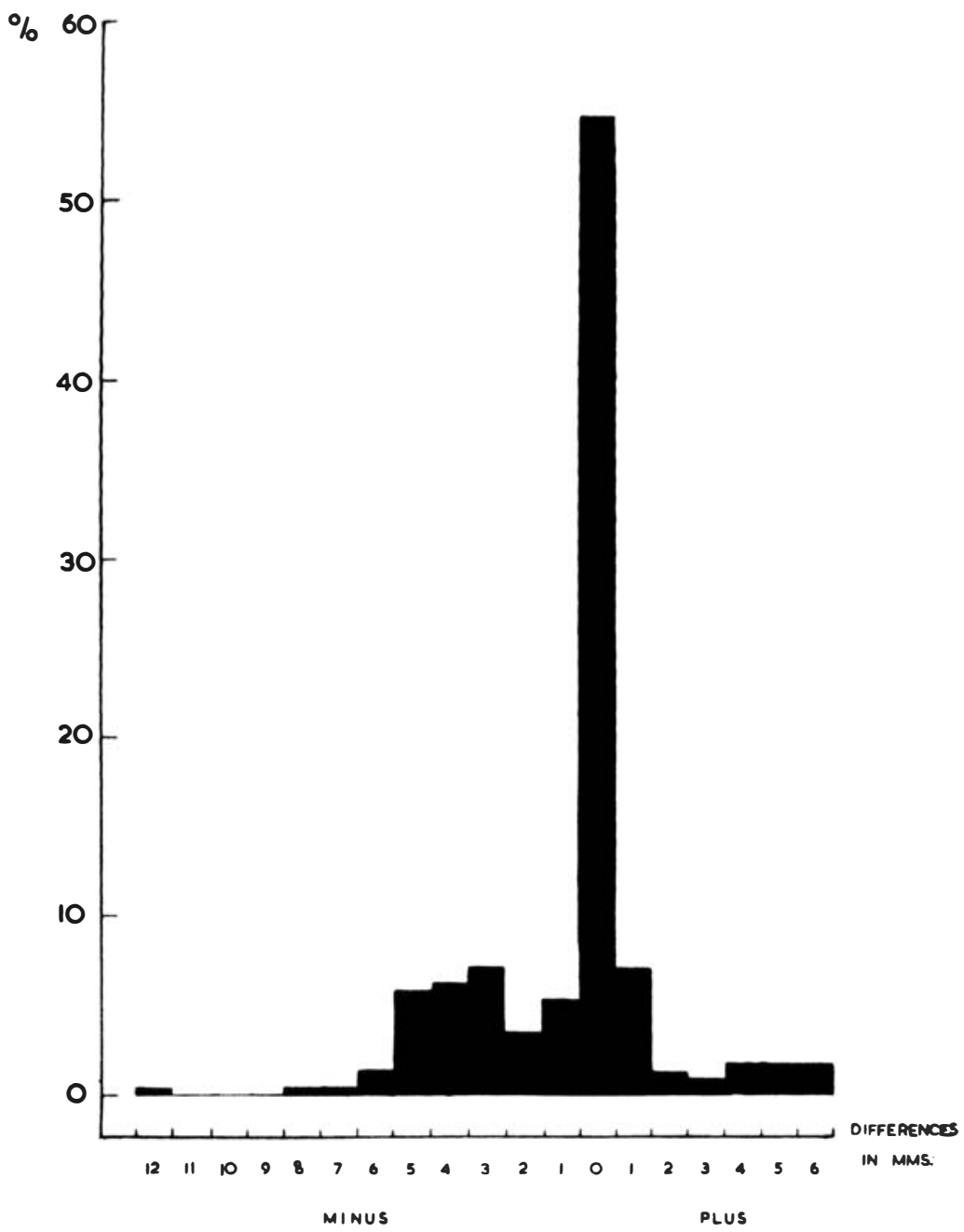

Histogram No. 1 shows the percentage frequency distribution of the differences in reaction between 5 T.U's of RT 22 and IT.U. of RT 23. (Reaction to 5 T.U. RT 22 minus reaction to 1 T.U. RT 23.) 


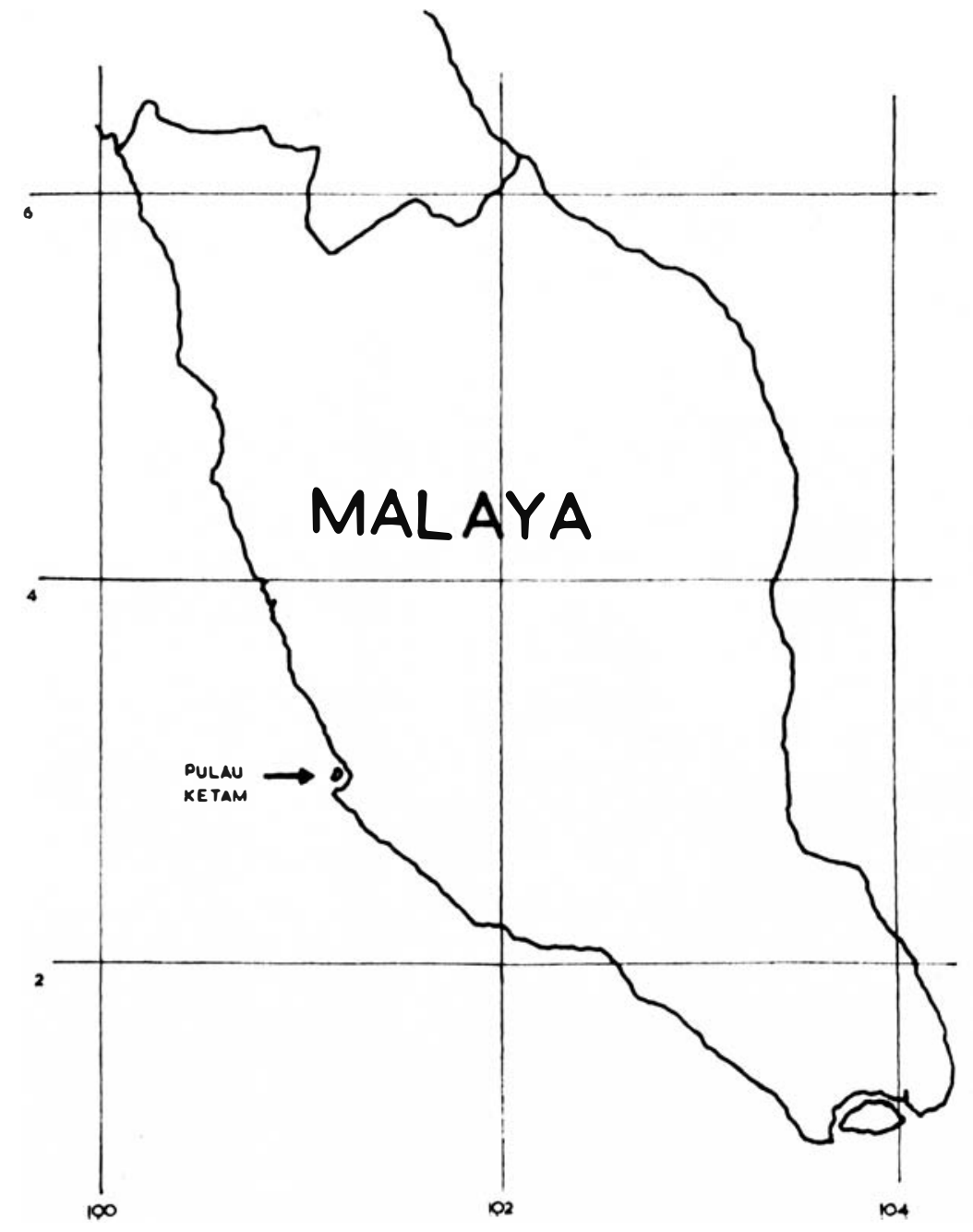


TABLE 2

The Tuberculin Reactions of the Population of 0-25 Years

\begin{tabular}{|c|c|c|c|c|c|c|c|c|c|c|c|}
\hline \multirow{2}{*}{$\begin{array}{c}\text { Age Group } \\
\text { in Years }\end{array}$} & \multirow{2}{*}{$\begin{array}{l}\text { Number } \\
\text { in Group }\end{array}$} & \multicolumn{10}{|c|}{ Tuberculin Reactions in mms. } \\
\hline & & $0-4$ & 5 & 6 & 7 & 8 & 9 & $5-9$ & $10-14$ & $15-19$ & 20 and over \\
\hline $0-5$ & 1442 & $1378(95.5 \%)$ & 23 & 8 & 3 & 3 & 3 & $40(2.8 \%)$ & $13(0.9 \%)$ & $3(0.2 \%)$ & $8(0.6 \%)$ \\
\hline $6-10$ & 1064 & $755(71 \%)$ & 93 & 56 & 31 & 25 & 16 & $221(20.7 \%)$ & $59(5.6 \%)$ & $15(1.4 \%)$ & $14(1.3 \%)$ \\
\hline $11-15$ & 642 & $297(46.3 \%)$ & 80 & 57 & 35 & 19 & 21 & $212(33 \%)$ & $88(13.7 \%)$ & $15(2.3 \%)$ & $30(4.7 \%)$ \\
\hline $16-20$ & 332 & $84(25.3 \%)$ & 37 & 40 & 25 & 18 & 20 & $140(42.2 \%)$ & $71(21.4 \%)$ & $14(4.2 \%)$ & $23(6.9 \%)$ \\
\hline $21-25$ & 169 & $32(18.9 \%)$ & 17 & 12 & 14 & 10 & 10 & $63(37.3 \%)$ & $44(26.0 \%)$ & $17(10.1 \%)$ & $13(7.7 \%)$ \\
\hline
\end{tabular}


however, the supply of this was discontinued and RT 23 was employed in equivalent strength which was $1 \mathrm{TU}$ in $0.1 \mathrm{ml}$. (Circular from Statens Serum Institut, Denmark, June, 1958). To ensure that these two tuberculins were identical in the doses employed, a group of 226 persons on the island were tested simultaneously with the two tuberculins on opposite arms. Histogram No. 1 gives the percentage frequency distribution of the differences between the two tuberculins. 1 unit of RT 23 gave a higher reading than 5 units of RT 22. (Mean difference 0.681 ; standard error of the mean difference $0.163 ; \mathrm{t}=4.18 ; \mathrm{P}<0.001)$. This difference is of interest as the true equivalent of 5 units of RT 22 is 0.7 unit of RT 23 . However, from the practical point of view the two tuberculins in the doses employed are very similar.

(b) The injections were given on the flexor surface of the forearm with a $1 \mathrm{ml}$. all glass tuberculin syringe and a No. $26 \mathrm{~g} . \times 7.5 \mathrm{~mm}$. platinum needle.

(c) The reaction was read at 48 hours in the majority of cases but a number were read at 72 hours. The reading was done with calipers which were read against a $\mathrm{mm}$. scale on a ruler. The maximum diameter of induration was read.

\section{Eligibility for BCG Vaccination}

The standard of eligibility for vaccination was that laid down by the World Health Organisation (WHO/TBC/Int./38.1957), which is that those persons with a reaction of $9 \mathrm{mms}$. or less to 5 TU or RT 22 tuberculin should be given BCG.

\section{Randomisation procedure for giving BCG}

The following procedure was followed:

1. Those eligible for BCG vaccination born in an odd year up to, and including 1957, were given BCG while those born in an even year were not vaccinated.

2. Those eligible for BCG vaccination born in 1958 and subsequently in an odd month were given BCG while those born in an even month were not vaccinated.

\section{BCG Vaccine}

The vaccine employed was the freeze-dried vaccine manufactured by Messrs. Glaxo Ltd., and the majority were vaccinated with batch numbers 148 and 146. It was administered by the same type of syringes and needles used for tuberculin but the two groups of syringes and needles were kept separate. The vaccine was given intradermally about the insertion of the deltoid muscle. When the vaccine was received from the distributors it was kept in a refrigerator; when required for use it was transported in a large thermos jar with ice. 
When a group of patients was assembled for vaccination an ampoule was removed from the thermos jar, rcconstituted, and used immediately.

\section{Record Keeping}

Adequate detailed and accurate records were absolutely essential to the trial. The secretary employed was a librarian with considerable knowledge of detailed record keeping and cross indexing. Records were initially entered into ledgers and subsequently the information was transferred to punch cards. Adequate space for follow up records was left in the ledgers and on the punch cards.

\section{Results}

1. The Leprosy Survey

In the 0-25 years group a total of 3,720 persons were examined clinically for leprosy. A total of 71 cases of leprosy was recorded as follows:

(a) Number of new cases found in the population 16

(b) Number of patients on the island discharged from Sungei Buloh Settlement

(c) Number of patients from the island at present in the Settlement

This gives an incidence of leprosy of 19 per thousand.

The age distribution of the persons with leprosy is given in Table 1 .

TABLE 1

The age distribution of leprosy in the 0-25 years age group Leprosy patients

$\begin{array}{cccc}\text { Age in years } & \text { Number in group } & \text { Number } & \text { Percentage } \\ 0-5 & 1442 & 0 & 0 \\ 6-10 & 1072 & 8 & 0.7 \\ 11-15 & 665 & 23 & 3.5 \\ 16-20 & 358 & 26 & 7.3 \\ 21-25 & 183 & 14 & 7.7\end{array}$

Of the 71 cases of leprosy, $49(69 \%)$ were lepromatous or atypical and $22(31 \%)$ were tuberculoid. $57(80 \%)$ of the patients were male and $14(20 \%)$ were female. The incidence in males was $57 / 1793$, i.e., 32 per thousand and in females 14/1927, i.e., 7 per thousand.

\section{Tuberculin Reactions}

The number of persons without clinical signs of leprosy who were given tuberculin was 3,649. Details of the tuberculin reactions are given in Table 2. Four hundred and twenty-seven persons were 

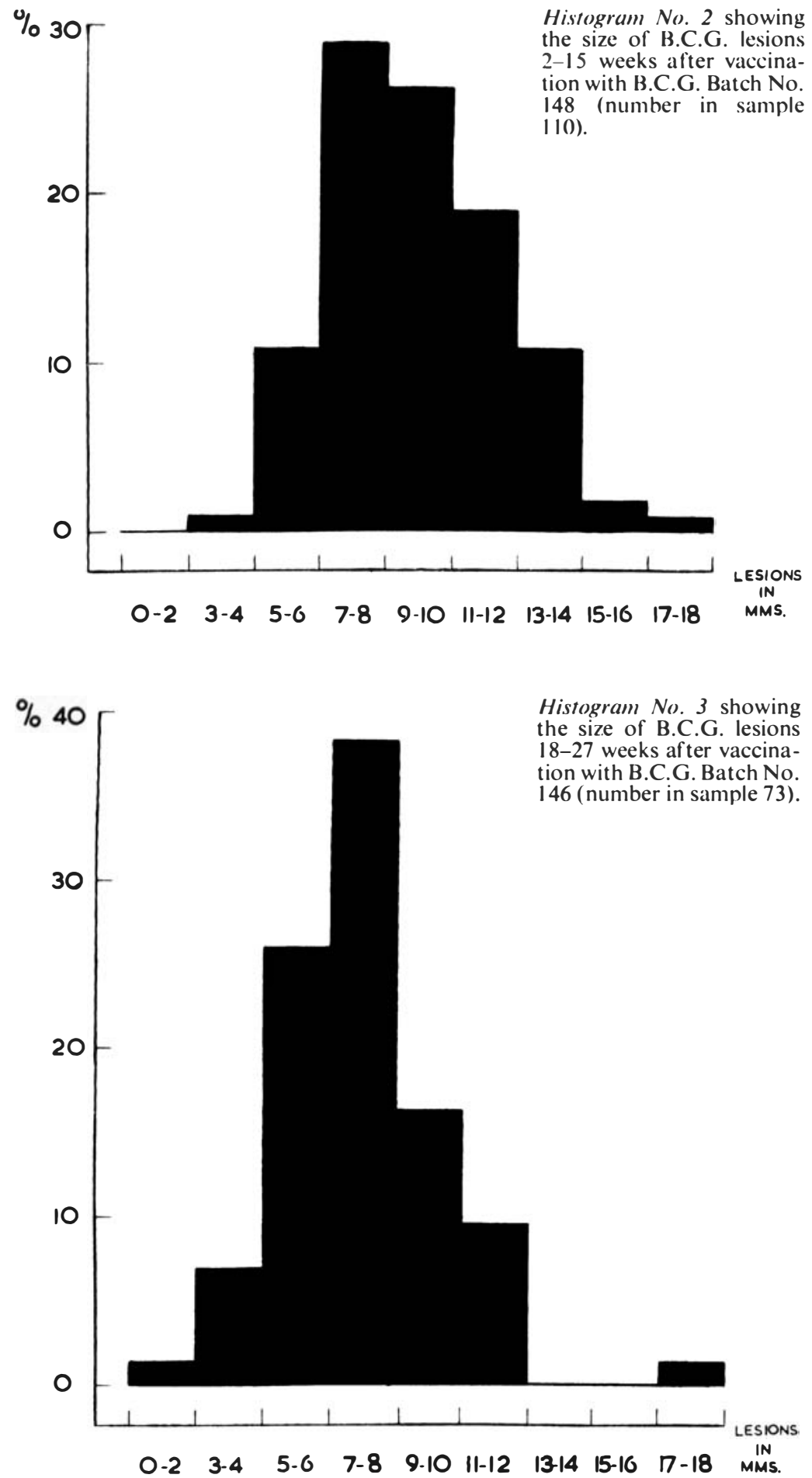
positive (induration of $10 \mathrm{mms}$. and over). The remaining 3,222 who were eligible for vaccination were randomized as described previously and 1,648 received $\mathrm{BCG}$ leaving 1,574 as controls.

\section{Response to $B C G$ Vaccination}

No untoward reactions to $\mathrm{BCG}$ vaccination were observed or reported. It was noticed that a number of persons applied some 'Chinese medicine' to the vaccination lesions in spite of our requests to leave them uncovered.

Random samples were taken of school children 2-15 weeks after vaccination with Batch No. 148 and 18-27 weeks after vaccination with Batch No. 146. The sizes of the lesions produced by the BCG were measured and these are shown in histograms 2 and 3. The mean diameter of the vaccine lesions produced by Batch No. 148 was $9.4 \mathrm{~mm}$. and by Batch No. $1467.2 \mathrm{~mm}$. In Britain the figure obtained with freeze dried BCG was $8.4 \mathrm{~mm}$. at 5-7 weeks and 7.9 at 10-17 weeks. (Preliminary Report to the Medical Research Council, 1958). These children were retested at the same time with tuberculin and the tuberculin conversions are given in Table 3 . The conversion rates

TABLE 3

The conversion rates for BCG Vaccine Batch Nos. 148 and 146

$\begin{array}{ccc}\text { BCG Batch } & \text { BCG Batch } & \text { British Freeze } \\ \text { No. } 148 & \text { No. } 146 & \text { Dried trials }\end{array}$

\begin{tabular}{|c|c|c|c|}
\hline \multirow{3}{*}{$\begin{array}{l}\text { Number in sample } \\
\text { Number absent on retest } \\
\text { Nos. converted to } 10 \mathrm{~mm} \text {. } \\
\text { or more }\end{array}$} & 110 & 74 & \multirow[t]{4}{*}{1772} \\
\hline & 0 & 5 & \\
\hline & $27(25 \%)$ & $28(41 \%)$ & \\
\hline $\begin{array}{l}\text { Mean diameter of these } \\
\text { reactions }\end{array}$ & $10.9 \mathrm{~mm}$. & $13.7 \mathrm{~mm}$. & \\
\hline \multicolumn{4}{|l|}{ Original reaction less } \\
\hline No. absent on retest & 0 & 2 & 0 \\
\hline \multicolumn{4}{|l|}{ No. converted to } \\
\hline $\begin{array}{l}\text { Mean diameter of these } \\
\text { reactions }\end{array}$ & $\begin{array}{r}7.2 \mathrm{~mm} \text {. } \\
\text { * to } 3 \mathrm{TU}\end{array}$ & $10.1 \mathrm{~mm}$. & $10.7 \mathrm{~mm}$ \\
\hline $\begin{array}{c}\text { Viable counts } \times 106 / \\
\text { Ex-works } \\
\text { Ex-Malaya }\end{array}$ & /ml. & $\begin{array}{l}\text { No. } 148 \\
.8 \\
.03\end{array}$ & $\begin{array}{c}\text { Batch No. } 146 \\
9.0 \\
1.1 / 2.7\end{array}$ \\
\hline
\end{tabular}


to $10 \mathrm{~mm}$. and over were $25 \%$ and $41 \%$ respectively for Batch Nos. 148 and 146. Comparable figures were not available from other trials as the standard of eligibility for vaccination employed was that only recently introduced by the World Health Organisation. The conversion rates to $5 \mathrm{~mm}$. or over were $79 \%$ and $63 \%$ compared to $90 \%$ in the British Freeze Dried Trials in 1958. An obvious cause of this lower conversion rate could have been a drop in the viable counts in the vaccine employed. Therefore samples of the batches employed were sent in refrigerated containers by air to London where the viable counts were performed. The results of these are given in Table 3 along with ex-works counts for the same batches. There had been a considerable fall in the viable counts particularly in Batch No. 148. It is considered likely that this was responsible for the lowered conversion rates obtained. It seems most unlikely that the fall could have occurred after the vaccine was received at Sungei Buloh Settlement as the material was kept refrigerated throughout. It appears however, that the damage may well have been done in the transport of the vaccine between the agents in Singapore and the consumer when there was a failure to maintain the vaccine at the recommended temperature.

\section{Discussion}

The initiation of the trial had its minor difficulties but on the whole the island proved to be an ideal place for the project. The ease of identification of houses and persons was an advantage which would be difficult to find elsewhere.

The incidence of leprosy found in the 0-25 years age group, namely 19 per thousand, was lower than expected. The reason for this is that many patients in Sungei Buloh Settlement who had stated that they had come from Pulau Ketam had in fact come from Indonesia and had been smuggled through the island to Malaya for treatment. The high reputation of Sungei Buloh Settlement was responsible for this desire for treatment in Malaya.

While an attempt was made to see everyone up to the age of 25 years, it is known that a number of persons were not seen. This applied particularly to the older groups. In the case of males, they often spent long periods at sea, and the females were shy of being examined. From census figures available from other parts of Malaya it seems that approximately $80 \%$ of the population from $0-25$ years were seen. It is now known that a number of cases of leprosy did not come forward. Certainly a number of ex-patients from the Settlement did not present themselves.

The pattern of age incidence of leprosy on the island is different from that found in Africa. As this was the first leprosy survey undertaken in Malaya no other figures are available from there for comparison. In Gambia (McFadzean and McCourt, 1955) 20\% of 


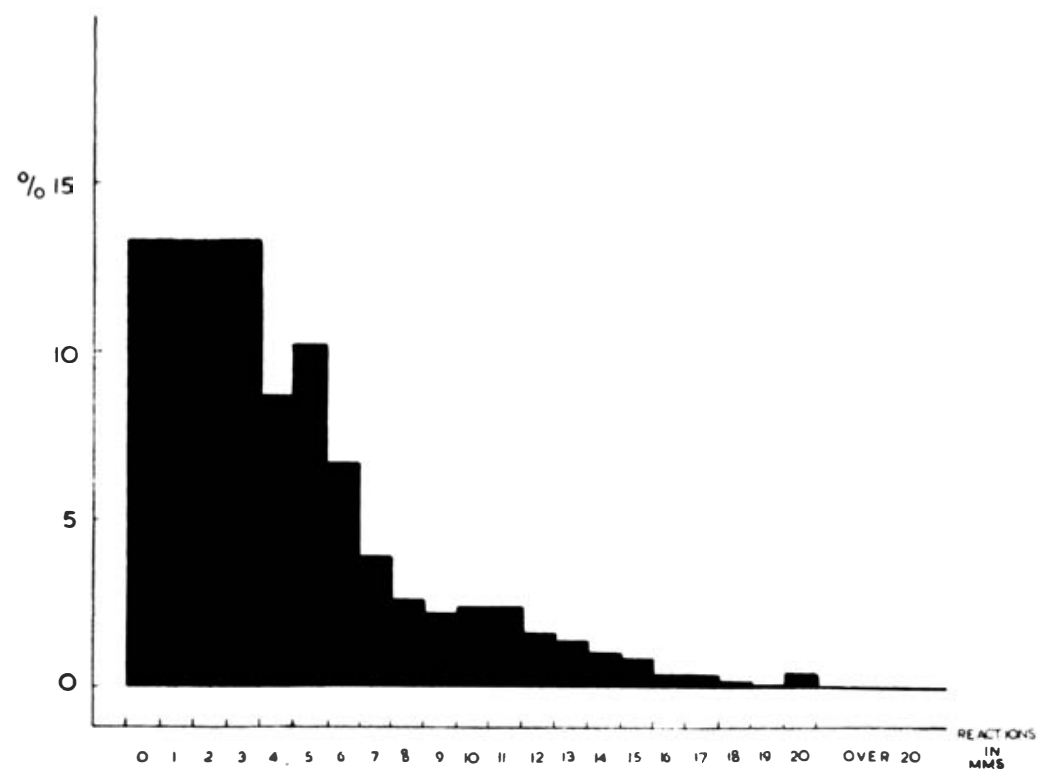

Histogram No. 4 showing the tuberculin reactions in the age group 6-15 years.

the cases of leprosy are found up to the age of 10 years while in the present survey only $11 \%$ occurred before the age of 10 .

The incidence of the type of leprosy also differs from that found in Africa. In Malaya $69 \%$ of the cases are lepromatous or atypical while in Gambia, for example, $70 \%$ of the cases were tuberculoid. On the island the incidence in males was significantly higher than that found in females, while in Gambia there was no difference in sex incidence.

To compare the incidence of tuberculin sensitivity on the island with that found elsewhere it is necessary to take a restricted age group such as shown in histogram No. $4.38 \%$ of the children from 6-15 years reacted to 5 TUs of RT 22 tuberculin with $5 \mathrm{~mm}$. or more. This is a similar reaction rate to that recorded in other parts of the tropics (WHO Document EB 24/5, May, 1959-Review of BCG Vaccination Programmes-Preliminary reports by the Director General).

The size of the lesions produced by the two batches of BCG and the subsequent reactions to tuberculin unfortunately cannot be compared directly owing to the different times after vaccination of making the observations. The tuberculin conversion rates with both batches of vaccine were lower than those obtained in Britain (see Table 2). The explanation for this lies almost certainly in the drop in the viable counts in the vaccines. It is clear that, particularly in the tropics, the method of handling and despatching the vaccine must 
receive greater supervision. As a further check viable counts should be made on samples of the batches of vaccine sent back to this country from the consumer. The major problem of tuberculosis now lies in underdeveloped tropical countries and it is to be expected that BCG vaccination will be widely undertaken in tropical areas. Unless adequate precautions are taken in supervising and checking the vaccine, control schemes may well be jeopardized.

\section{The Future of the Trial}

The data have been kindly analysed by Dr. Ian Sutherland and it is estimated that, allowing for losses, the number of cases in the unvaccinated group which can be expected over 10 years is 30 . This means that no benefit could be claimed from BCG vaccination unless the apparent degree of protection was $50 \%$ or more. As a level of less than $50 \%$ protection is of little value or interest this part of the trial is certainly worth continuing.

The expected addition to the number of cases by extending the intake to include successive generations of new-borns is very small and this part of the trial is not worth continuing and has been abandoned.

It is clear that the introduction of a nation-wide BCG vaccination project in Malaya would, for ethical reasons, almost certainly result in the abandonment of the trial.

\section{Summary}

The initiation of a controlled trial of BCG vaccine as a prophylactic for leprosy is described. The trial is being undertaken on an island off the West Coast of Malaya. 3,720 persons in the age group 0-25 years were examined. The incidence of leprosy found was 19 per thousand with a significantly higher incidence among males. 3,649 persons with no clinical signs of leprosy were tuberculin tested. Of these, 3,222 were eligible for vaccination with BCG and by randomization 1,648 were vaccinated and 1,574 left as controls. The expected incidence of leprosy in the unvaccinated group over the next 10 years would be sufficient to demonstrate a level of protection of the vaccine of $50 \%$ or more. The expected incidence of leprosy in the new born intake is too low to give significant results and this part of the trial has been abandoned. It is intended that the present population of 0-25 years be examined for leprosy at intervals for the next 10 years.

The conversion rate after vaccination was lower than expected and this was due almost certainly to a fall in the viable count of the vaccine employed. It is clear that much care must be taken in handling BCG vaccine especially in the tropics and it is suggested that in future trials the viable counts of the vaccine should be checked after it has reached the consumer. 


\section{Acknowledgments}

Grateful acknowledgments are due to many people in Malaya including the Director of the Institute for Medical Research; the State Medical and Health Officer, Selangor; the Medical Superintendent, Sungei Buloh Settlement; the District Officer and Chinese Affairs Officer, Klang; the Harbour Master, Port Swettenham; the Chief Police Officer, Selangor; the Chairman and Committee Members, Pulau Ketam and to our staff Miss Macpherson, Mr. Chua Cheong Teik, Mr. Sembakutty and Mr. Appokutan.

We are grateful to Dr. P. D'Arcy Hart, C.B.E., Dr. Ian Sutherland, and to Dr. R. J. W. Rees for advice and to Dr. T. W. Osborn who kindly undertook the viable counts of the vaccines. We are also grateful to Miss E. J. Kinsley and Miss M. Mussett who undertook some of the statistical analyses.

The freeze dried BCG vaccine was kindly supplied by Glaxo Laboratories.

\section{References}

McFadzean, J. A. and McCourt, M., 1955, Leprosy Review, $26,57$.

Preliminary Report to the Medical Research Council, 1958, Brit. Med. J. 1, 79. 